\title{
Do "Current" Teaching Methodologies Really Work in Every Context?
}

\author{
Aynur Yürekli \\ School of Foreign Languages, İzmir University of Economics, Turkey
}

Copyright $\bigcirc 2017$ by authors, all rights reserved. Authors agree that this article remains permanently open access under the terms of the Creative Commons Attribution License 4.0 International License

\begin{abstract}
This study examines the impact that learners have on the effective implementation of the Communicative Language Teaching Approach (CLT) in monolingual English for Academic Purposes (EAP) class in a country where English is taught as a foreign rather than second language. Based on recorded language lessons of four different learner groups, it discusses to what extent students affect classroom interaction patterns, content-creation and the type of questions which are asked during the lessons. It further relates these to the level of accomplishment of the students under study. In the analysis of the recorded lessons, frequency distributions for question types, percentages for interaction patterns and arithmetical averages for success rates have been calculated. The findings suggest that the teaching/learning context, learners specifically, have an influence on the time spent on pair and group work; the contribution to the academic content required to fulfill the task at hand, and the number of display, referential and elicitation questions asked by the teacher. It suggests that context specific issues have a determinant effect on the implementation of communicative teaching approaches. Not only during the implementation stage but also in the final assessments and evaluations, learner's impact seems to play a crucial role. This, inevitably, highlights the need for post methodology in language teaching. It specifically focuses on teachers' ongoing professional development needs so that their teaching methodologies come into line with the needs of the specific learner groups that they are working with. It also suggests that methodologies that are 'current' or proven 'effective' may not necessarily work in teaching and learning contexts from which they originated.
\end{abstract}

Keywords Post-methodology, CLT, Learner Differences, EFL

\section{Introduction}

The discussion over methods, their relative advantages, pitfalls, strengths and weaknesses has been continuing for many years, (Savignon, 2007; Maghsoudi, 2016) but the debate has recently shifted dramatically towards postmethod perspectives. A review of recent literature clearly reveals that the context in which teaching and learning takes place determines the effectiveness of a method (Kumaravadivelu, 1994), to such an extent that it is the principles or techniques, rather than methods, that are considered to dominate the English Language Teaching (ELT) setting.

The focus on methods has been criticized on various grounds, specifically in regard to Communicative Language Teaching (CLT) (Littlewood, 2014) and its relevance to contexts where English is being taught as a Foreign Language, which Kachru (1996) refers to as the expanding circle; i.e. counties where English is taught/learned as a foreign language. Despite the obstacles involved in adapting CLT in such a way as to make it an appropriate method in the English as a Foreign Language (EFL) context, many institutions within the expanding circle claim to have a communicative approach to language teaching (Richards, 2006). As the need for individuals who can communicate effectively in English has increased, CLT has gained popularity, in many cases accompanied by Task-based Language Teaching (TBLT) (Littlewood, 2007).

However, trying to adapt the teaching principles of a method that originated in the western world to cultures and circumstances of countries outside has also created problems at the implementation stage. Various concerns have been voiced on the applicability of communicative methodologies, the major ones being "classroom management, avoidance of English, minimal demands on language competence, incompatibility with public assessment demands and conflict with educational values and traditions" (Littlewood, 2007: 244). Efforts to resolve these conflicts have inevitably drawn both teachers and scholars to the idea of postmethodology, which moves teachers away from "prepackaged and structured methods" (Canagarajah, 2016: 20) towards creating teaching conditions that directly relate, to and cater for, the needs of 
their immediate teaching context.

Originally, CLT was developed in the western English speaking countries, where the aim was to develop communicative competence in learners who needed to live and survive in English language environment (Hiep, 2007). Yet, it had enormous impact on the learning contexts that are not rich in real target language use, and offer limited exposure to English. The profession has reached a point where teachers are being asked to implement the basics of CLT in a context that it does not apply to. Teachers are provided with training regarding tasks and techniques to effectively apply CLT in classrooms; however, the main issue seems to be the lack of learners' familiarity with the communicative classroom, the nature of CLT itself, and external factors limiting the use of authentic English outside the classroom.

\section{CLT Indicators}

In a typical CLT classroom, whether the focus is EAP or general English, there are some indicators which reflect the type of techniques used in the particular teaching approach taken. One of the major indicators is the classroom interaction pattern. As Richards (2006) and Griffiths (2011) point out, the amount of time spent on pair work and group work is one of the defining features of CLT. Another indicator is the focus on meaning/content rather than language form. The final feature of the CLT classroom is a student rather than teacher centered environment, in which genuine communication is encouraged as much as possible, often achieved through the use of questions to generate real language use.

\section{Classroom Interaction}

A language class with an overt emphasis on communication is expected to exhibit patterns of student-student interaction; i.e. pair or group work. Thus, an observation of such a class should show examples of teacher-whole class activities, student-student(s) activities and student individual work. The duration of each interaction type also is a reflection of the extent to which students are actively engaged in real communication.

\section{Content Versus Form}

In CLT classes, especially with a TBLT perspective, creating the content for the task to be completed by students plays a crucial role. Apart from providing input via authentic texts, student contributions to the content of the lesson, supported by the teacher, is also a feature of communicative and purposeful language use. Thus, the relative contributions of the teacher and students on lesson content, as opposed to language form is an indication of students' active engagement in content creation (Griffiths, 2011).

\section{Question Types}

"Questions and answers (Q and A) form a high percentage of classroom activities that are supposed to get the learners involved in creation or recreation of meaning through language" (Chastain, 1988: 142)". Questions are also one of the most commonly used strategies by teachers to organize and enrich the classroom discourse. Therefore, the analysis of questions asked by the teacher and the information that questions generate are worth considering.

There are three types of questions. The first type, which are referred to as display questions, are those that do not require deep thinking skills, but are used to check memory or to make students reproduce an obvious answer. Display questions usually require one word or short phrases as answers; and as such, they do not serve real communication purposes (Behnam \& Pouriran, 2009). The answer to a display question has usually one correct answer. The second type is referential questions. These require a genuine response from students, and usually the teacher does not know the answer in advance. Referential questions are exploratory and encourage students to give longer and more complex answers among a range of possible or alternative answers. The last type is elicitation questions, which covers questions that are neither referential nor display. The purpose of asking elicitation questions, which Behnam \& Pouriran (2009) label as "Socratic Questions", is to ask for content related input or to check existing knowledge of students-both linguistic and content-wise. The responses to elicitation questions can have more than one possible answer.

It is worth noting, though, that not all questions have communicative value. Bearing in mind that display questions are a reproduction of already acquired knowledge, referential and elicitation questions can be claimed to have a more effective impact on creating a communicative teaching/learning environment.

\section{The Teaching Context}

There are several factors involved in the successful implementation of a method or approach, and the key one is inevitably the context in which the teaching/learning takes place (Griffiths, 2011). The importance of context even implies that methods can be replaced by postmethodologies shaped by the context and the needs of specific learner groups in different cultures according to the influence of external factors. Within this defined context, the role of the learner has a determinant effect on the successful implementation of classroom practices. Thus, irrespective of the experience and professional status of the teacher, the facilities and opportunities offered by the institution and a range of other environmental factors, particularly the learners and the dynamics they create play a crucial role in shaping the learning environment.

Like China, Japan, Egypt, Poland, the Netherlands or Russia, Turkey is within the expanding circle and as such, 
English is being taught as a foreign language, with the main language exposure and language use generally limited to the classroom environment. In Turkey, the majority of higher education institutions, an intensive foundation language programme is offered, followed by an obligatory Freshmen English course.

In the institution where the study was conducted, after completing a one-year intensive general English language programme, learners start content studies conducted in English. In their freshmen year, all students take an EAP course which centers on content and language input, aiming at raising the learners' awareness about academic genre and conventions based on oral and written communicative tasks to offer language practice with specific content. It is task-based in nature, yet each teaching unit follows a communicative approach, so as to enable students to use the language in an academic context. Therefore, it is possible to state that all students involved in this study have a similar learning context.

This study aims at looking at how the local context, especially the nature of learners, affects the way certain teaching principles and techniques related to CLT are implemented. To achieve this aim, the following questions guide the research:

(a) Do learner dynamics affect classroom interaction patterns?

(b) Do learner dynamics affect the content creation during the lesson?

(c) Do learner dynamics affect the questioning behavior of the teacher?

\section{Method}

\section{The Sample}

Four groups of students enrolled in the EAP courses offered in the 2016-2017 Academic year spring semester formed the sample for the study. Table 1 shows the details of the groups.

Table 1. Female/Male distribution of groups

\begin{tabular}{cccc}
\hline & Female (n) & Male (n) & Total (n) \\
\hline Group 1 & 7 & 16 & 23 \\
Group 2 & 13 & 10 & 23 \\
Group 3 & 12 & 14 & 26 \\
Group 4 & 11 & 12 & 23 \\
\hline Total & 43 & 52 & 95 \\
\hline
\end{tabular}

The age range of the students in the study was between 19 and 22. Students were from various departments, including engineering, psychology, sociology, culinary arts, communication sciences, business, international relations, and design. They all share the same native language, i.e. Turkish; however the medium of instruction is English. To control any intervening variables, especially the teacher factor, all four groups were instructed by the same instructor. In brief, all 4 groups were taking the same course, covering the same material, and were in the same age group, sharing the same mother tongue, and had the same course instructor.

\section{Data Collection}

While collecting the data, four 50-minute lessons from each of the four groups (a total of 16 lessons) were recorded using lecture capture software. The software (Panopto) allows the use of two permanent cameras in each classroom; one teacher camera, and one student camera, which makes it possible to record all aspects of the classes. Even though lessons were scheduled as 50 minutes, in the analysis, time spent on taking attendance, general reminders and instructions for the upcoming lessons were excluded. Thus the analyzed lesson time varied between 42.2 and 49.1 minutes per lesson.

\section{Analysis}

The total recording time for four lessons of group 1 was 180.4 minutes, for group 2, 183.9 minutes, for group 3, 177.4 minutes and for group 4, 181.5 minutes. The recorded lessons were first transcribed, and then analyzed in terms of interaction patterns, content input, and question types used by the teacher. The software enabled the tracking of interaction types and lengths of time for each, to the nearest second.

\section{Findings}

\section{Classroom Interaction}

Four types of interaction patterns were observed and recorded: a) Teacher-whole class, which is mainly teacher-fronted and guided, addressing the whole class and asking for whole group participation, without addressing or nominating particular students; b) pair work, which requires students to work with a partner to complete a task; c) group work, which requires students to interact in a group to complete a task; and d) individual work, which requires students to work alone. The majority of individual work was for listening/reading tasks or writing tasks. Chart-1 below shows the percentage of minutes spent on each interaction type for the total of four lessons per group. 


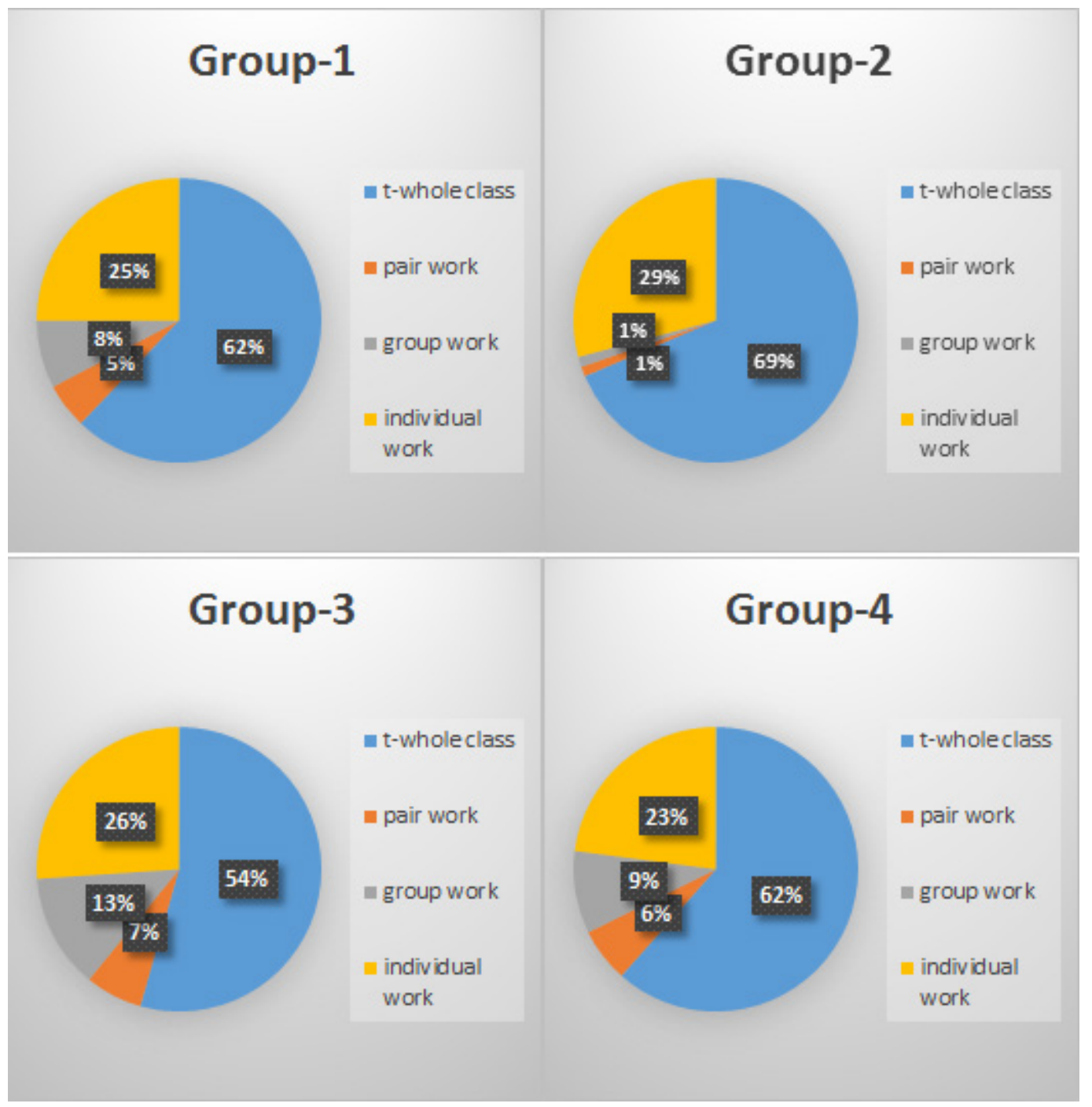

Chart 1. Distribution of interaction patterns

In all four cases, the dominant interaction pattern is teacher-whole class followed by individual student work. Then, group work is followed by pair work for all groups except for group 2 . The distribution clearly shows that, in terms of classroom interaction as required by the principles of CLT, the lessons allow limited time for student to student interaction and communication. In terms of a continuum regarding how 'communicative' each class is, group 3 appears to have the most communication with a total of $20 \%$ of student-student interaction. However, despite the fact that almost all classroom procedures are the same in all four groups, including the course instructor, group-2 reflects a much more traditional, and much less a communicative classroom.

\section{Content Creation}

As mentioned earlier, a typical CLT classroom has a dominant focus on content and meaning rather than on form. Because of the nature of the English course under study, for each unit, students are expected to complete either an oral or a written task by using the content input provided by the course book and the input collaboratively created during the lesson. Thus, a significant amount of time during the lesson is spent creating the input content that the students are expected to reuse. In this section, the analysis has been based on the number of instances in which the instructor gave feedback (FB) on content, number of instances in which students provided input and the number of instances in which the instructor focused primarily on form. The topic was 'Coca-Cola' versus Pepsi's advertising strategies'. Examples of each type of feedback are as follows:

Teacher's feedback on content: "Pepsi uses celebrities more in their commercials"

Student's feedback on content: "Shakira was also in Pepsi commercials"

Teacher's feedback on form: "We don't say advertisings, we say advertisements".

The frequency distributions of contributions to content creation are demonstrated in Table 2.

Regarding input on content, the contribution of students 
is lowest in group 2, followed by 1 and 4 . Group 3 has the highest contribution, with a percentage of 43,03 , which is closer to the level of input provided by the teacher. These figures reflect the level of student participation and involvement, and their contribution to a communicative classroom atmosphere by providing content input. Figures clearly indicate that in group 2, student involvement was minimal, thus teacher provided most of the input, revealing in a less student-oriented, more teacher-centered lesson.

Table 2. Frequency distribution of Teacher and Student FB on content

\begin{tabular}{|c|c|c|c|c|c|}
\hline & \multicolumn{2}{|c|}{ Teacher FB on Content } & \multicolumn{2}{|c|}{ Student FB on Content } & \multirow{2}{*}{ Total } \\
\cline { 1 - 5 } & $\mathrm{f}$ & $\%$ & $\mathrm{f}$ & $\%$ & \\
\hline Group 1 & 41 & 77,35 & 12 & 22,64 & 53 \\
\hline Group 2 & 65 & 90,27 & 7 & 9,72 & 72 \\
\hline Group 3 & 45 & 56,96 & 34 & 43,03 & 79 \\
\hline Group 4 & 40 & 64,51 & 22 & 35,48 & 62 \\
\hline
\end{tabular}

As for teacher's orientation towards content versus form, Table 3 shows the instances of focus on content in relation to focus on form.

Table 3. Frequency distribution of Teacher's FB on form and content

\begin{tabular}{|c|c|c|c|c|c|}
\hline & \multicolumn{2}{|c|}{ Teacher FB on Content } & \multicolumn{2}{|c|}{ Teacher FB on Form } & \multirow{2}{*}{ Total } \\
\hline & $\mathrm{f}$ & $\%$ & $\mathrm{f}$ & $\%$ & \\
\hline Group 1 & 41 & 60,29 & 27 & 39,70 & 68 \\
\hline Group 2 & 65 & 71,42 & 26 & 28,57 & 91 \\
\hline Group 3 & 45 & 73,77 & 16 & 26,22 & 61 \\
\hline Group 4 & 40 & 72,72 & 15 & 27,27 & 55 \\
\hline
\end{tabular}

In all instances, the instructor clearly focuses more on content than on form with figures above $50 \%$, which is in line with the principles of CLT. However, it is worth noting that there is a difference between groups, and considerable difference between groups 1 and 3 , reflecting a more content-focused approach for group 3.

\section{Question Types}

Questions take up a considerable time in the language classroom (Chastain, 1988); therefore, it was considered important to analyse them based on their purpose. Below are examples reflecting each of the three categories:

Display question: "Which word is used as synonym for "adequate"? (the answer is given in the reading text).

Referential question: "Why do you prefer Pepsi rather than Coca-Cola?" (the answer is open-ended and the teacher cannot predict).

Elicitation Question: "What other words could we use to describe the taste of Coke?" (more than one answer is possible and it is neither in the text nor predetermined by the teacher).

The total number of questions coded in a total 16 class observed was 227 for group 1, 280 for group 2, 182 for group 3 and 189 for group 4. Chart 2 shows the distribution of question types for each group. (For a detailed frequency distribution of question types for each recorded lesson, see Appendix-3)

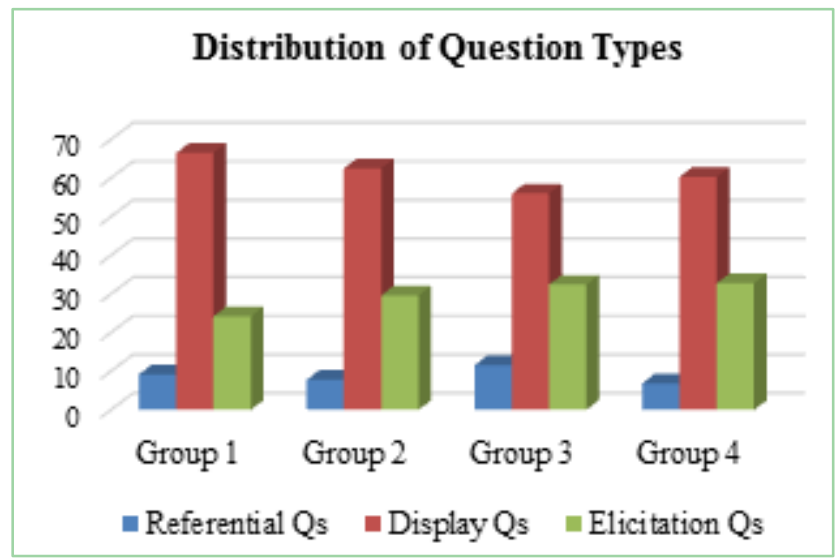

Chart 2. Distribution of Question types

In language classes display questions are most widely used in classroom interaction (Allwright \& Bailey, 1991); yet, referential questions generate more complex and lengthy responses and contribute more to the communicative nature of the classroom, reflecting a more authentic interaction pattern. In all four groups, display questions outnumbered the other question types. In terms of general distribution, group 3 seems to reflect a more balanced use of question types, whereas the questions used in groups 2 and 4 , and in particular 1, reflect the dominance of display questions. The ratio of elicitation questions, as opposed to display questions, is also worth noting. Even though elicitation questions are not as output-generating as referential questions, these are valuable tools as they give the teacher a chance to elicit "unknown" responses, which are not necessarily short. Elicitation questions are the second most commonly used type in all four groups, with the highest percentages in groups 3 and 4 .

\section{Results, Conclusions and Recommendations}

The results of the study suggest that, even in situations in which students are similar in terms of age group, nationality, institution, expectations and needs, differences between students and classes impact the general atmosphere of the immediate learning context. It is clear from the findings that the teacher in this study exhibits different behavior in terms of the degree to which lessons are teacher-fronted, as evident from the amount of time dedicated to student-centered tasks; from her focus on content versus form; and from the question types chosen. All three domains covered in the analysis of the recorded lesson are potential indicators of CLT. There is at least 
some evidence of all of these indicators in each group; nevertheless, it seems that across groups, at best, the principles of CLT are only being partially implemented.

Teacher training studies in ELT frequently highlight the importance of teacher training as part of professional development, as it offers individuals a chance to familiarize themselves with the many approaches and techniques in the area. Moreover, teacher training equips individuals with pedagogical practice skills and techniques necessary for their profession. However, as Canagarajah (2016) points out, it is important that more attention is given on how to deal with circumstances specific to the context of learning. There is a need to integrate the postmethodology perspective into the training scope to make teachers more aware of their own particular teaching setting, and also to perceive methods and approaches as guides, rather than unquestionable rules. As learners are one of the main factors influencing the effective implementation of certain principles and approaches, a greater focus should also be placed on learner training and classroom management.

Regarding professional development, there are already many studies highlighting the importance of self-reflection (Brandt, 2008) and action research (Burns, 2010) for professional development. However, greater emphasis should be placed on these concepts, particularly in pre-service training, to allow teachers to increase awareness of changes in student population and their needs.

Another interesting point relates to the evaluation and appraisal of language teachers. In many countries and institutions, classroom observations are a part of the appraisal system of teachers. The results of this study clearly show that conclusions based on a limited number of observations of only one learner group may lead to misinterpretations about the teacher's effectiveness. Bearing in mind that learners are one of the key factors affecting the classroom behavior of the teacher, observations of a particular teacher by administration should be triangulated with different groups of learners.

\section{REFERENCES}

[1] Allwright, D. and Bailey, K.M. (1991). Focus on the Language Classroom. Cambridge: CambridgeUniversity Press.

[2] Behnam, B. and Pauriran, Y. (2009). 'Classroom discourse: analyzing teacher/learner interactions in Iranian EFL task-based classrooms'. Porta Linguarum, 117-132.

[3] Brandt, C. (2008). 'Integrating feedback and reflection in teacher preparation'. ELT Journal 62/1: 37-46.

[4] Burns, A. (2010). Doing Action Research in English Language Teaching: A Guide for Practitioners. New York: Routledge.

[5] Canagarajah, S. (2016). "TESOL as a professional community: a half-century of pedagogy, research, and theory'. TESOL Quarterly 50/1: 7-41.

[6] Chastain, K. (1988). Developing Second Language Skills: Theory and Practice. Orlando, Florida: Harcourt Brace Jovanovich, Inc.

[7] Griffiths, C. (2011). 'The traditional/communicative dichotomy’. ELT Journal 65/3: 300-308.

[8] Hiep, P. H. (2007). 'Communicative language teaching: unity within diversity'. ELT Journal, 61/3: 193-201.

[9] Kachru, B. (1996). 'The paradigms of marginality'. World Englishes 15: 241-255.

[10] Kumaravadivelu, B. (1994). 'The post method condition: emerging strategies for second/foreign language teaching'. TESOL Quarterly 28: 27-48.

[11] Kumaravadivelu, B. (2006). 'TESOL methods: changing tracks, challenging trends'. TESOL Quarterly 40/1: 59-81.

[12] Littlewood, W. (2007). 'Communicative and task-based language teaching in east asian classrooms'. Language Teaching 40/3: 243-249.

[13] Littlewood, W. (2014). 'Communication-oriented language teaching: Where are we now? Where do we go from here?' Language Teaching, 47/3: 349-362.

[14] Maghsoudi, N. (2016). 'Post method pedagogy: a plausible choice in Iran?'. Studies in English Language Teaching 4/2: 282-288

[15] Richards, J. C. (2006). Communicative Language Teaching. New York: Cambridge University Press. 